\title{
All a Matter of Scale: The Good, the Bad, and the Ugly of Zirconology
}

\author{
S.A. WILDE ${ }^{1 *}$, M.A. KUSIAK ${ }^{2}$, AND M.J. WHITEHOUSE ${ }^{3}$
}

'School of Earth \& Planetary Sciences, Curtin University, Perth, Western Australia (*correspondence: s.wilde@curtin.edu.au)

Institute of Geophysics, Polish Academy of Sciences, Warsaw, Poland (monika.kusiak@igf.edu.pl)

${ }_{3}^{3}$ Swedish Museum of Natural History, Stockholm, Sweden (Martin Whitehouse@nrm.se)

Techniques in zircon geochronology have advanced rapidly in recent years, with particular emphasis placed on both increasing the rapidity of analyses and reducing the volume of material analyzed. The former has resulted in a profusion of publications that have led to a much better understanding of the global age distribution of rocks and zircons from the Hadean to the Recent. The ability to analyze ever-smaller crystal volumes has likewise resulted in a greater appreciation of the complexity of both igneous and metamorphic zircon, allowing discrimination of multiple events within single grains. However, now that we can investigate minerals at the nano- and atomic scales, it is evident that element distribution is not always as simple and ordered as once believed. Although it has been known for decades that lead $(\mathrm{Pb})$ could be lost (and gained?) by zircon, it was not until clusters of radiogenic $\mathrm{Pb}$ were identified by isotopic ion imaging [1], and the later discovery of metallic lead nanospheres [2], both in UHT metamorphic rocks from the Napier Complex in Antarctica, that the potential effects on in situ geochronology were fully appreciated. Radiogenic $\mathrm{Pb}$ clusters and metallic $\mathrm{Pb}$ nanospheres have now been identified in zircons from several high-grade terranes and it has been established they have the potential to affect the accuracy of SIMS analyses. Furthermore, it is not only $\mathrm{Pb}$ that is known to be mobile and the implications of the redistribution of these various elements in igneous and metamorphic zircon will be evaluated.

[1] Kusiak et al. (2013) Geology 41, 291-294. [2] Kusiak et al. (2015) PNAS 112, 4958-4963. 